\title{
Krashignyan: A Farmer Support System
}

\author{
Pragati Kanchan, \\ Dept. of CSE, MIT School of Engineering, \\ MIT ADT University \\ Pune, India \\ pragatikanchan04@gmail.com
}

\author{
NikhilKumar Shardoor, \\ Professor, Dept. of CSE, MIT School of Engineering, \\ MIT ADT University \\ Pune, India
}

\begin{abstract}
Agriculture is the primary component of the Indian economy. It is the primary source of food supply and is essential to our livelihoods. The majority of Indians rely on agriculture for their employment. Agriculture production declines as a result of unpredictable weather, wrong selection of crops, unbalanced fertilizer use, and a lack of market awareness. Farmers face numerous challenges in traditional farming, and many times, farmers fail to select the appropriate crop for cultivation. Crop growth is affected by a variety of factors such as weather, soil parameters, and fertilizers. A crop recommendation system is proposed in this paper to assist farmers in selecting the appropriate crop based on the location, weather data, crop sowing season, and soil parameter. Various Machine Learning techniques, such as Decision Tree (DT), Random Forest (RF), Gaussian Naive Bayes, and XGBoost Classifier methods, were used for recommendation. The XGBoost classifier gives the best results with a $97 \%$ accuracy, hence the final model was developed using the XGBoost classifier. This system will help farmers in selecting the best crop for their fields while increasing agricultural yield.
\end{abstract}

Keywords-Crop Recommendation, Decision Tree, Random Forest, Naive Bayes, XGBoost Classifier.

\section{INTRODUCTION}

India is an agricultural country. Agriculture is considered the primary occupation of the majority of Indians. It contributes about $17 \%$ to the total GDP and employs more than $50 \%$ of the workforce[16]. Agriculture is the prime source of food production and also supplies raw materials to various industries. Population growth drives up food demand[2]. Farming needs to be done in an effective way to increase food production. Farmers face numerous challenges in traditional farming, and many times, farmers fail to select the appropriate crop for cultivation. A farmer selects a crop based on the recommendations of other farmers without knowing whether or not that crop is appropriate for his farm, which sometimes resulting in crop loss. There are different factors like weather conditions, soil parameters, use of fertilizers that affect crop growth. With uncertain nature, it gets difficult for farmers to grow a healthy crop. If the farmer knows in advance which crop is best for his farm based on these factors, he will definitely benefit in farming. With the help of technology, it is possible to recommend the best crop for a farmer's field based on environmental, soil, and other parameters. Nowadays, technological advancements in the agriculture field help farmers in increasing crop yields. In this paper, a crop recommendation system is proposed using machine learning technology to help farmers in choosing the best crop for their farm. Machine Learning (ML) is one of the most widely used technologies in the current technological era. It is the subfield of AI, and its widely used for analysis, classification, regression, and forecasting purposes. Nowadays, in various disciplines such as healthcare, finance, agriculture, automotive, machine learning is used. Machine learning techniques assist in the development of an intelligent system that learns from experience and makes data-driven decisions. In the agriculture field, different machine learning techniques, such as supervised, unsupervised techniques, are used to analyze different data patterns for better decision-making. Krashignyan: A Farmer Support System is proposed in this paper to help farmers in selecting the best crop based on their location, weather data, crop sowing season, and soil parameter. Various Machine Learning techniques, such as Decision Tree (DT), Random Forest (RF), Gaussian Naive Bayes, and XGBoost Classifier methods, were used for recommendation. XGBoost classifier gives the best results, so the final model was built using an XGBoost classifier. This system will help farmers in selecting the best crop for their fields while increasing agricultural yield.

\section{LITERATURE SURVEY}

Archana, K. et al.[1] in this paper developed a system using a voting-based ensemble classifier to recommend the most appropriate crop, fertilizer, and to predict crop yield. The proposed system recommends a suitable crop for cultivation based on Nitrogen $(\mathrm{N})$, Potassium $(\mathrm{K})$, Phosphorus(P), soil type, soil texture, land type, $\mathrm{pH}$, electric conductivity, and temperature parameters. The proposed system also suggest fertilizers to farmers for recommended crop and predict crop yield. The author also developed a crop rotation module, in which alternative crops except predicted crops were suggested to farmers based on crop cultivation seasons.

Chaudhari, A. et al.[2] in this paper proposed a platform for crop recommendation and its optimal seed price using shopbot. A dataset with the following parameters - crop, rainfall, temperature, season, year, production, area, and the location used for crop recommendation. Dataset was normalized and split into a 7:3 ratio. Various data mining techniques were applied to the dataset, and there accuracy score was calculated. A suitable crop is recommended using the classification algorithm. In their work, for optimal pricing of seeds, web scraping was performed using the selenium framework. The authors found that the Decision Tree Classifier gave better accuracy for crop recommendation.

Kelvin Tom Thomas et al.[3] in his work proposed a recommendation system, which recommends the most suitable crop based on soil parameters to the farmers. The different machine learning techniques like Decision Tree(DT), K-Nearest Neighbor(KNN), KNN with crossvalidation, Naive Bayes were used to train a model. A dataset with the following soil parameters - soil NPK values, soil $\mathrm{pH}$ values, and most suitable crop was used for prediction. The author found that KNN with cross-validation 
gives better results. The final system has built using KNN. Based on the record present in their dataset value for ' $\mathrm{k}$ ' has taken as 10. The proposed model predicts the most suitable crop by taking soil NPK and soil $\mathrm{pH}$ values.

Lavanya B et al.[4] in this paper presented a crop prediction system using data analytics techniques in the form of an android application. The dataset used in this study includes the following parameters: weather, soil type, soil $\mathrm{pH}$, previous three harvests, fertilizers, season, and market demand. Initially proposed system take input from farmers like details of previous three harvest, availability of water and the data of weather conditions, temperature and soil condition are taken based on users location In their system, based on collected data from users and the dataset available, a suitable crop for cultivation was predicted by applying machine learning techniques.

Nischitha K. et al.[5] in this paper designed a crop recommendation system for particular land using machine learning techniques. In their work, developed system that predict the crop based on weather data and soil parameters, like temperature, humidity, soil $\mathrm{pH}$, and rainfall. The dataset includes parameters such as temperature, humidity, rainfall, crop data, soil $\mathrm{pH}$, and NPK values. For rainfall prediction, separate rainfall prediction model was built using Support Vector Machine Classifier with Radial Basis Function (RBF) kernel to predict rainfall. For crop recommendation, input parameters were entered manually from the user or taken by sensors, and the suitable crop predicted using the Decision Tree algorithm

Kulkarni, N. H.[6] et al. in this paper designed a crop recommendation system using the Ensembling Technique. The proposed model predicts suitable crop based on soil dataset. The dataset was preprocessed and split into a 75:25 ratio. The ensemble model was build using Random Forest, Naive Bayes, and linear Support Vector Machine. The result of individual learners was combine based on the majority voting technique.

Mythresh A et al.[7] in this paper developed a crop prediction application using machine learning technology. The proposed system predicts the crop based on land suitability. Various parameters such as soil parameters, weather parameters, temperature, rainfall, and so on were considered. The naive Bayes technique was used for crop prediction.

Pudumalar, S. et al.[8] in this paper proposed a recommendation system using ensemble learning technique for crop recommendation based on soil characteristics. The ensemble model was build using Random Forest, Naive Bayes, K- Nearest Neighbors, and Chi-squared Automation Interaction Detection (CHAID). The result of individual learners was combine based on the majority voting technique. In their work for crop recommendation, various soil parameters like depth, texture, $\mathrm{pH}$, soil color, permeability, water holding, drainage, and erosion were considered.

Shinde, M. et al.[9] designed a system to recommend a crop and fertilizers to farmers to increased crop yield. Farmers can use this system through an android based mobile application. This system suggests fertilizers to farmers based on past purchased history using the Apriori algorithm. For crop recommendation, the Random Forest algorithm was used. The designed application allows the farmer to purchase fertilizer from the shopping portal.

Kumar, A. et al.[10] in this paper proposed a recommendation system to predict the suitable crop and to suggest pest control techniques to farmers. In his work Decision Tree Algorithm, Support Vector Machine Classification Algorithm, and Logistic Regression Algorithm applied to crop prediction model. The author found that SVM Classification gave better accuracy as compared to other algorithms used. The proposed model predicts the most suitable crop based on soil parameters.

Banavlikar, T. et al.[11] proposed a neural network-based crop recommendation system. The following parameters like soil moisture, temperature, and humidity are used for crop recommendation. Three sensors, DHT11, humidity sensor, and soil moisture sensor, were used in the proposed system to measure temperature, humidity, and soil moisture.

Zeel Doshi et al.[12] presented an intelligent crop recommendation system. The proposed system recommend crop based on environmental parameters, farm geolocation, and soil characteristics. Also implemented another model for rainfall prediction using Linear Regression, which predicts rainfall for the next 12 months. Decision Tree, K Nearest Neighbors, Random Forest, and Neural Network techniques were used for crop recommendation. Their proposed model provides a map visualization feature that helps the farmer decide which crop to grow.

Kalimuthu, M. et al.[13] in this paper proposed a crop prediction system using machine learning technique in the form of an android application. The dataset used in this study includes the following parameters: soil moisture, soil $\mathrm{pH}$, rainfall, temperature, humidity. Dataset was split into a 7:3 ratio. A Naive Bayes Gaussian classifier with boosting algorithm was used for prediction.

Patil, A. et al.[14] introduced crop recommendation system using a machine learning classification algorithm. The dataset used in this study includes the climatic parameters, soil parameters, and production parameters. Three classification algorithms like Decision Tree, KNN, and Naive Bayes algorithm, were used and their performance was compared.

Dhruv Piyush Parikh et al.[15] in this paper, a crop recommendation model has been built using machine learning technology. The proposed system recommends a suitable crop based on $\operatorname{Nitrogen}(\mathrm{N}), \operatorname{Potassium}(\mathrm{K})$, Phosphorus $(\mathrm{P})$, temperature, humidity, $\mathrm{pH}$, and rainfall parameters. The different machine learning techniques like Support Vector Machine(SVM), Logistic Regression, and Random Forest Classifier were used to train a model. The author found that Random Forest Classifier gives better results. The final system has been built using Random Forest Classifier.

We learned from the survey that both soil and weather parameters are important for crop prediction, and the survey also helped us in selecting the best machine learning techniques for prediction.

\section{PROPOSED MODEL}

Figure 1 depicts the system architecture of the crop recommendation model. Whereas in the first stage, the dataset is collected and preprocessed before being used to 
train the machine learning model. The crop dataset with the following parameters - Temperature, Humidity, Soil Moisture, Soil Type, Crop Season, and Crop label is considered for a recommendation. The machine learning model was trained using various machine learning algorithms, and the model with the best prediction results was chosen. Once training is completed and the model built, the built model is deployed using the web application framework Flask. These all process is done at the backend. The user enters data into a web application that serves as the user interface. The web app makes an API request, and the loaded model gives a response.

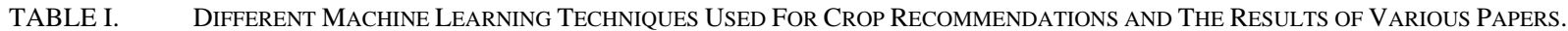

\begin{tabular}{|c|c|c|c|c|}
\hline AUTHOR & DATASET & TECHNIQUES & PARAMETERS & ACCURACY \\
\hline Archana, K. et al. [1] & $\begin{array}{l}\text { Agriculture Crop Soil } \\
\text { Dataset. }\end{array}$ & $\begin{array}{l}\text { Voting-based Ensemble } \\
\text { Classifier: } \\
\text { Chi-square Automatic } \\
\text { Interaction Detection, } \\
\text { Random Forest, } \\
\text { Naive Bayes. }\end{array}$ & $\begin{array}{l}\text { Soil Parameters - N, } \mathrm{P}, \mathrm{K} \text {, } \\
\text { soil type, soil texture, land } \\
\text { type, temperature, } \mathrm{pH} \text {, } \\
\text { electric conductivity. }\end{array}$ & $92 \%$ \\
\hline Chaudhari, A. et al. [2] & $\begin{array}{l}\text { Climatic conditions dataset. } \\
\text { data.gov.in }\end{array}$ & $\begin{array}{l}\text { Data Mining Techniques : } \\
\text { Classifiers - } \\
\text { Decision Tree, Extra Tree, } \\
\text { ExtraTreesClassifier (with } \\
\text { ensemble), Random Forest, } \\
\text { K-Neighbors, } \\
\text { Web Scraping. }\end{array}$ & $\begin{array}{l}\text { Year, area, location, season, } \\
\text { crop, rainfall, temperature, } \\
\text { production. }\end{array}$ & $\begin{array}{l}\text { DecisionTreeClassifier: } 87 \% \text {, } \\
\text { RandomForestClassifier: } 86 \%\end{array}$ \\
\hline $\begin{array}{l}\text { Kelvin Tom Thomas et } \\
\text { al.[3] }\end{array}$ & - & $\begin{array}{l}\text { Machine Learning } \\
\text { Techniques - } \\
\text { SVM, KNN, KNN with } \\
\text { cross validation, DT, Naive } \\
\text { Bayes. }\end{array}$ & $\begin{array}{l}\text { Soil value - N, P, K, and } \\
\text { pH , Corresponding crops. }\end{array}$ & $\begin{array}{l}\text { KNN: } 85 \% \text {, } \\
\text { DT: } 81 \%, \\
\text { Naive Bayes: } 82 \% \text {, } \\
\text { SVM: } 78 \%\end{array}$ \\
\hline Lavanya, B. et al. [4] & - & Data Analytics Technique. & $\begin{array}{l}\text { Previous three harvests, Soil } \\
\text { type, soil pH, weather, } \\
\text { season, fertilizers, market } \\
\text { demand. }\end{array}$ & - \\
\hline Nischitha K. et al. [5] & $\begin{array}{l}\text { Government website, V C } \\
\text { Farm Mandya, Weather } \\
\text { department. }\end{array}$ & $\begin{array}{l}\text { SVM Classifier, Decision } \\
\text { Tree. }\end{array}$ & $\begin{array}{l}\text { Soil } \mathrm{pH} \text {, and NPK values, } \\
\text { temperature, humidity, } \\
\text { rainfall, crop data. }\end{array}$ & - \\
\hline Kulkarni, N. H. et al. [6] & $\begin{array}{l}\text { Dataset consists of climatic } \\
\text { details, soil chemical and } \\
\text { physical properties. } \\
\text { data.gov.in }\end{array}$ & $\begin{array}{l}\text { Ensemble model with } \\
\text { majority voting technique. } \\
\text { Random Forest, } \\
\text { Naive Bayes, and } \\
\text { Linear SVM. }\end{array}$ & $\begin{array}{l}\text { Soil type, soil pH values, } \\
\text { NPK content of soil, } \\
\text { Surface temperature, Avg. } \\
\text { rainfall, Surface } \\
\text { temperature, and sowing } \\
\text { season. }\end{array}$ & Average accuracy $99.91 \%$ \\
\hline Mythresh A, et al.[7] & $\begin{array}{l}\text { Soil site suitability dataset, } \\
\text { Crop requirement dataset. }\end{array}$ & Naive Bayes. & $\begin{array}{l}\text { Slope, soil texture, depth, } \\
\text { gravel, rocky, erosion, } \\
\text { drainage and pH mapped to } \\
\text { survey IDs, conditions } \\
\text { required for crop growth. }\end{array}$ & $60 \%$ \\
\hline Pudumalar, S. et al. [8] & Madurai district. & $\begin{array}{l}\text { Ensemble model with } \\
\text { majority voting technique: } \\
\text { KNN, Random tree, Naive } \\
\text { Bayes. }\end{array}$ & $\begin{array}{l}\text { Depth, texture, } \mathrm{pH} \text {, soil } \\
\text { color, permeability, } \\
\text { drainage, water holding and } \\
\text { erosion, crop. }\end{array}$ & - \\
\hline Kumar, A. et al. [10] & Soil, Crop Dataset. & $\begin{array}{l}\text { Logistic regression, SVM } \\
\text { classification, Decision } \\
\text { Tree. }\end{array}$ & $\begin{array}{l}\text { Avg. rainfall, temperature, } \\
\text { soil color, } \mathrm{pH} \text {. }\end{array}$ & SVM: $89.66 \%$ \\
\hline Banavlikar, T. et al.[11] & $\begin{array}{l}\text { Dataset consists of Soil } \\
\text { Moisture, Humidity, } \\
\text { Temperature. }\end{array}$ & Neural Network. & $\begin{array}{l}\text { Soil Moisture, Humidity, } \\
\text { Temperature. }\end{array}$ & - \\
\hline Doshi, Z. et al. [12] & $\begin{array}{l}\text { India Agriculture and } \\
\text { Climate } \\
\text { Data Set. }\end{array}$ & $\begin{array}{l}\text { Machine learning } \\
\text { techniques: } \\
\text { Multi-label classification } \\
\text { KNN, Decision Tree, }\end{array}$ & $\begin{array}{l}\text { Precipitation, temperature, } \\
\text { location parameters, soil } \\
\text { and meteorological } \\
\text { parameters, }\end{array}$ & $\begin{array}{l}\text { Rainfall Predictor linear } \\
\text { regression: } 71 \% \\
\text { Decision Tree: } 90.20 \% \\
\text { K-NN: } 89.78 \%\end{array}$ \\
\hline
\end{tabular}




\begin{tabular}{|l|l|l|l|c|}
\hline & & $\begin{array}{l}\text { Random Forest, } \\
\text { Neural Network, Linear } \\
\text { Regression. }\end{array}$ & $\begin{array}{l}\text { soil type, aquifer thickness, } \\
\text { soil pH, thickness of } \\
\text { topsoil. }\end{array}$ & $\begin{array}{l}\text { Random Forest: 90.43\% } \\
\text { Neural Network: 91.00\% }\end{array}$ \\
\hline Kalimuthu, M. et al.[13] & $\begin{array}{l}\text { Seed Data, Soil Nature, and } \\
\text { Climatic conditions Data. }\end{array}$ & $\begin{array}{l}\text { Naive Bayes Gaussian } \\
\text { classifier. }\end{array}$ & $\begin{array}{l}\text { Soil moisture, soil pH, } \\
\text { rainfall, temperature, } \\
\text { humidity. }\end{array}$ & $97 \%$ \\
\hline $\begin{array}{l}\text { Dhruv Piyush Parikh et } \\
\text { al.[15] }\end{array}$ & $\begin{array}{l}\text { Crop Recommendation } \\
\text { Dataset. } \\
\text { Kaggle }\end{array}$ & $\begin{array}{l}\text { SVM, Logistic regression, } \\
\text { Random Forest classifier. }\end{array}$ & $\begin{array}{l}\text { Temperature, humidity, N, } \\
\text { P, K, pH, rainfall. }\end{array}$ & \\
\hline
\end{tabular}

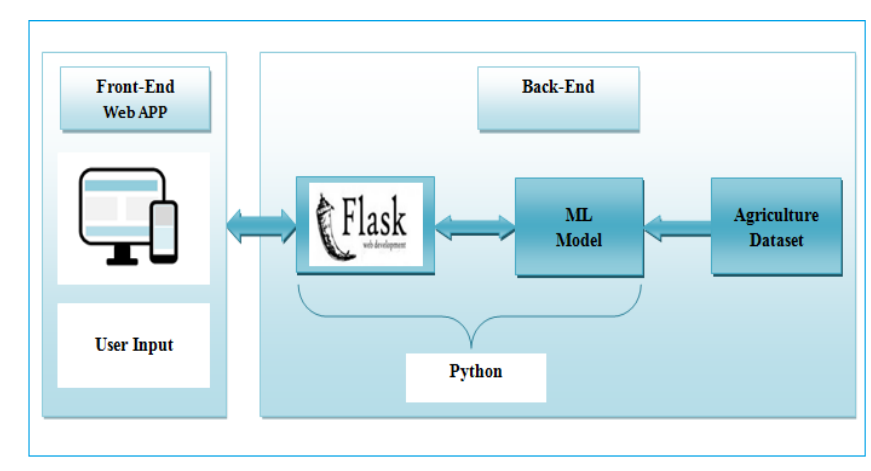

Fig. 1. System Architecture of Crop Recommendation System

\section{Machine Learning Model :}

As illustrated in Figure 2, In the first step, the crop dataset was collected. Two distinct datasets were collected and merged based on similar crop labels. The prepared dataset contains the following parameters - temperature, humidity, soil moisture, soil type, crop sowing season, and crop label for the Pune district. After finalizing data in the next step data is preprocessed. Data Pre-processing is the most important task because the collected dataset mostly contains missing values, which affect the accuracy of the model. Data were preprocessed and then divided into two datasets: training and testing. $75 \%$ of data was used for training, while $25 \%$ was kept for testing model performance. The four machine learning classification algorithms like the Decision Tree, Random Forest, Gaussian Naive Bayes, and XGBoost Classifier were used for training the prediction model. After training performance of these four techniques was compared. The final model has been built using XGBoost Classifier. Following the model training, a predictive model was developed, which will predict a suitable crop for cultivation based on user input.

\section{Techniques:}

\section{Decision Tree (DT):}

The most often used supervised machine learning technique for solving both regression and classification problems is a decision tree. It created a tree-like structure and divided the entire data set into smaller sub-parts based on certain conditions. The root node in the decision tree represents the whole sample, while the leaf node represents the outcome based on the decision made. Initially, all the independent variables are the candidate for the root node in the decision tree. Different attribute selection criteria, such as Information Gain and the Gini Index, are used to determine which attribute to chose as the root node and subsequent node. The root node is compared with record attributes to predict label or class. The below equation shows the formula for calculating the Gini Index.

$$
\operatorname{Gini}(\mathrm{D})=1-\sum_{\mathrm{i}=0}^{\mathrm{n}} \mathrm{P}_{\mathrm{i}}^{2}
$$

Where $P_{i}$ is a relative frequency of class $i$ in dataset D. Attribute with lowest Gini index should be preferred.

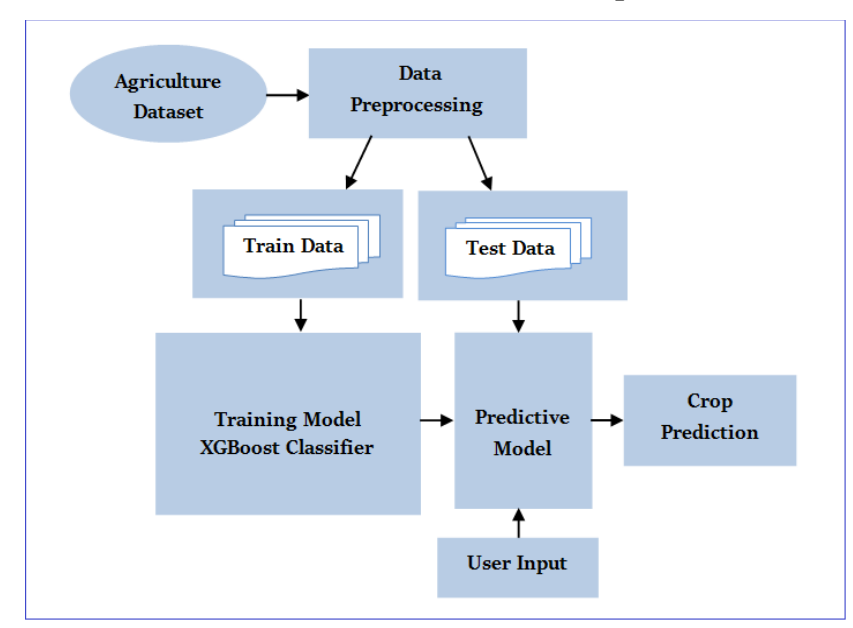

Fig. 2. Machine Learning (ML) Model

\section{Random Forest (RF):}

Random Forest is also one of the most popular supervised machine learning techniques used for solving both regression and classification problems. It's consists of multiple decision trees and uses decision trees in a randomized way. It uses decision trees of different shapes and sizes. Random Forest is an ensemble classifier as it comprises multiple decision trees, and the final decision is taken based on the majority of votes.

\section{Naive Bayes (NB):}

Naive Bayes is a supervised machine learning technique used for solving classification problems. It is a probabilistic classifier that can solve binary as well as multiclass classification problems. It is based on the Bayes theorem and assumes that the features in the dataset are independent of one another. In this study, the Gaussian Naive Bayes algorithm has used. Gaussian Naive Bayes algorithm assumes that features follow a normal distribution. The below equation shows the formula for calculating the Gaussian Probability Density Function.

$$
\mathrm{P}(\mathrm{x} \mid \mathrm{y})=\frac{1}{\sqrt{2 \pi \sigma^{2}}} e^{\left(-\frac{(\mathrm{x}-\mu)^{2}}{2 \sigma^{2}}\right)}
$$

Where $\sigma$ represents standard deviation and $\mu$ is the mean.

\section{XGBoost Classifier:}

XGBoost stands for extreme gradient boosting. It's a decision tree-based boosting algorithm. The XGBoost technique is used to solve problems involving classification, 
regression, and prediction. It is implemented on top of the gradient boosting framework. This technique runs at a fast speed and with high accuracy. It performs better on small to medium datasets. It uses the parallelization concept. It prevents the model from overfitting and also prevents trees from growing beyond a certain size.

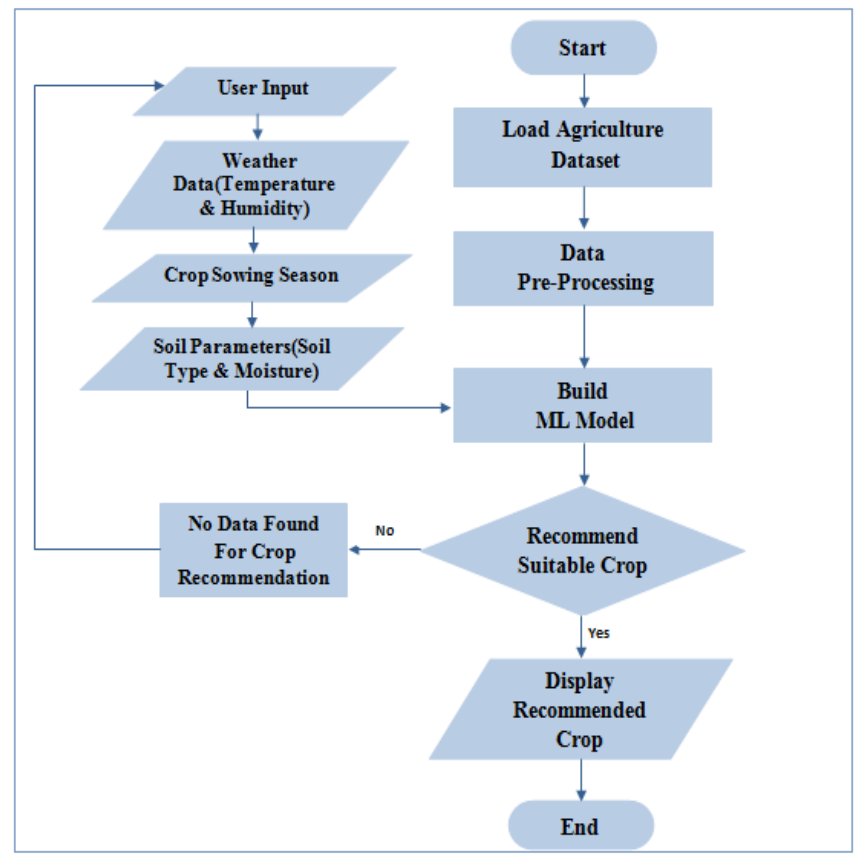

Fig. 3. Flowchart of Crop Recommendation System

\section{Crop Recommendation:}

Based on the soil parameters, crop season, and weather data, the proposed model will help to predict the best crop for cultivation for the Pune district. In this study, the user's input for crop recommendation includes location, soil moisture, soil type, and crop season. Based on data entered by the user suitable crop is predicted with the help of machine learning techniques. The XGBoost classifier was used for crop recommendation.

\section{RESULTS AND DISCUSSION}

\section{Experimental Setup:}

For crop recommendations, the datasets were downloaded from Kaggle and data.gov.in websites. The exact dataset was not found, so the dataset was prepared using collected datasets. Based on available datasets, the following parameters are considered in the proposed model; Climatic Parameters: Temperature, Humidity, Soil Parameters: Soil Moisture, Soil Type, and Crop Season. Two distinct datasets were collected and merged based on similar crop labels.

The first dataset collected (District-wise-season-wisecrop-production dataset) includes the following parameters: State Name, District Name, Crop Year, Season, Crop, Area, and Production, as shown in figure 4 . This dataset has been downloaded from the Kaggle and data.gov.in website. The data of the Pune district was taken from the given dataset. There are a total of 495 records for the Pune district in the given dataset.

\begin{tabular}{|c|c|c|c|c|c|c|c|c|}
\hline & & B & C & & $D$ & $E$ & $F$ & \\
\hline 1 & State_Name & District_Name & Crop_Year & & Season & Crop & Area & Productior \\
\hline 2 & Maharashtra & PUNE & & 1997 & Autumn & Maize & 4 & 4570 \\
\hline 3 & Maharashtra & PUNE & & 1997 & Kharif & Arhar/Tur & 3900 & 2900 \\
\hline & Maharashtra & PUNE & & 1997 & Kharif & Bajra & 135700 & 112000 \\
\hline 5 & Maharashtra & PUNE & & 1997 & Kharif & Gram & 43400 & 26100 \\
\hline 6 & Maharashtra & PUNE & & 1997 & Kharif & Jowar & 4200 & 5200 \\
\hline 7 & Maharashtra & PUNE & & 1997 & Kharif & Maize & 4400 & 4700 \\
\hline 8 & Maharashtra & PUNE & & 1997 & Kharif & Moong(Gr & 2800 & 1200 \\
\hline 9 & Maharashtra & PUNE & & 1997 & Kharif & Pulses tot & 203 & 91 \\
\hline 10 & Maharashtra & PUNE & & 1997 & Kharif & Ragi & 12200 & 9800 \\
\hline & Maharashtra & PUNE & & 1997 & Kharif & Rice & 59400 & 66000 \\
\hline 12 & Maharashtra & PUNE & & 1997 & Kharif & Sugarcane & 40900 & 39227 \\
\hline 13 & Maharashtra & PUNE & & 1997 & Kharif & Total fooc & 2456 & 2113 \\
\hline 14 & Maharashtra & PUNE & & 1997 & Kharif & Urad & 2300 & 1200 \\
\hline & Maharashtra & PUNE & & 1997 & Rabi & Jowar & 510800 & 235000 \\
\hline 16 & Maharashtra & PUNE & & 1997 & Rabi & Maize & 6900 & 10300 \\
\hline 17 & Maharashtra & PUNE & & 1997 & Rabi & Other Rak & 790 & 33 \\
\hline 18 & Maharashtra & PUNE & & 1997 & Rabi & Wheat & 57300 & 71400 \\
\hline 19 & Maharashtra & PUNE & & 1997 & Summer & Maize & 1200 & 2200 \\
\hline & Maharashtra & PUNE & & 1997 & Whole Ye & : Cotton/lin & 2 & 600 \\
\hline 21 & Maharashtra & PUNE & & 1998 & Kharif & Arhar/Tur & 3900 & 1100 \\
\hline 22 & Maharashtra & PUNE & & 1998 & Kharif & Bajra & 150000 & 110900 \\
\hline 23 & Maharashtra & PUNE & & 1998 & Kharif & Castor set & 200 & 100 \\
\hline 24 & Maharashtra & PUNE & & 199 & Kharif & Cotto & 300 & 500 \\
\hline & Maharashtra & PUNE & & 1998 & Kharif & Groundnu & 45000 & 66100 \\
\hline
\end{tabular}

Fig. 4. District-wise-season-wise-crop-production dataset

The second dataset (Fertilizer prediction dataset) downloaded from the Kaggle, has the following parameters Temperature, Humidity, Moisture, Soil Type, Crop, Nitrogen, Potassium, Phosphorous, Fertilizer Name, as shown in figure 5 . The given dataset contains a total of 99 records.

\begin{tabular}{|c|c|c|c|c|c|c|c|c|c|}
\hline 4 & & B & c & D & $E$ & & G & H & \\
\hline 1 & Temparature & Humidity & Moisture & Soil Type & Crop & Nitrogen & Potassium & Phosphorous & Fertilizer Name \\
\hline 2 & 26 & 52 & & 8 Sandy & Maize & 37 & & & 0 Urea \\
\hline 3 & 29 & 52 & & 5 Loamy & Sugarcan $€$ & 12 & & & 36 DAP \\
\hline 4 & 34 & 65 & & 2 Black & Cotton & 7 & & & 30 14-35-14 \\
\hline 5 & 32 & 62 & & 4 Red & Tobacco & 22 & & & $2028-28$ \\
\hline 6 & 28 & 54 & & 6 Clayey & Paddy & 35 & & & 0 Urea \\
\hline 7 & 26 & 52 & & 5 Sandy & Barley & 12 & 1 & & 13 17-17-17 \\
\hline 8 & 25 & 50 & & 4 Red & Cotton & 9 & & & $1020-20$ \\
\hline 9 & 33 & 64 & & 0 Loamy & Wheat & 41 & & 0 & 0 Urea \\
\hline 10 & 30 & 60 & & 2 Sandy & Millets & 21 & & & $1828-28$ \\
\hline 11 & 29 & 58 & & 3 Black & Oil seeds & 9 & & 7 & 30 14-35-14 \\
\hline 12 & 27 & 54 & & 8 Clayey & Pulses & 13 & & 0 & 40 DAP \\
\hline 13 & 31 & 62 & & 8 Sandy & Maize & 14 & & & 12 17-17-17 \\
\hline 14 & 25 & 50 & & 5 Loamy & Cotton & 36 & & & 0 Urea \\
\hline 15 & 32 & 62 & & 1 Clayey & Paddy & 24 & & & $2228-28$ \\
\hline 16 & 26 & 52 & & 1 Red & Ground $\mathrm{N}$ & 14 & & & 41 DAP \\
\hline 17 & 31 & 62 & & 9 Black & Sugarcane & 10 & 1 & & $1417-17-17$ \\
\hline 18 & 33 & 64 & & 4 Clayey & Pulses & 38 & & 0 & 0 Urea \\
\hline 19 & 25 & 50 & & 9 Sandy & Barley & 21 & & 0 & $1928-28$ \\
\hline 20 & 28 & 54 & & 5 Black & Cotton & 39 & & & 0 Urea \\
\hline 21 & 29 & 58 & & 2 Loamy & Wheat & 13 & & 0 & 36 DAP \\
\hline 22 & 30 & 60 & & 4 Sandy & Millets & 10 & & 0 & $920-20$ \\
\hline 23 & 34 & 65 & & 3 Loamy & Sugarcane & 12 & 1 & & 12 17-17-17 \\
\hline 24 & 35 & 68 & & 3 Red & Tobacco & 11 & & 0 & 37 DAP \\
\hline 25 & 28 & 54 & & 7 Black & Millets & 36 & & 0 & 0 Urea \\
\hline
\end{tabular}

Fig. 5. Fertilizer prediction dataset

These two datasets were merged based on similar crop labels. The Unique() command was used to search for unique crop labels in both datasets. After examining both datasets, it was found that there are a total of eight crop labels that are common among both datasets. Maize, Sugarcane, Cotton, Wheat, Millets, Oilseeds, Pulses, and Groundnuts are the crop labels that are similar in both datasets. So datasets have been merged based on similar crop labels.

\begin{tabular}{|c|c|c|c|c|c|c|c|c|c|c|c|}
\hline \multirow{3}{*}{$\begin{array}{l}1 \text { A } \\
1 \text { State Name } \\
2 \text { Maharashitra }\end{array}$} & \multirow{2}{*}{$\stackrel{\text { B }}{\text { Distrit Name }}$} & \multirow{2}{*}{\multicolumn{2}{|c|}{\begin{tabular}{c|c}
$C$ & $D$
\end{tabular}}} & \multirow{2}{*}{\begin{tabular}{c|c|c}
$E$ & $F$ \\
Prodution Season
\end{tabular}} & & & & & \multicolumn{2}{|l|}{ L M } & \multirow{2}{*}{ 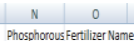 } \\
\hline & & & & & Temporature H. & dity 1 & ture Soll Type & crop & Nitrogen Potassiur & & \\
\hline & PUNE & 1997 & & $4 \quad 4570$ Autumn & 26 & 52 & $38 \sin 6$ & Naire & 37 & 0 & OUrea \\
\hline 3 Matrasshtra & PUNE & 1997 & & 4550 Autumn & 31 & 62 & $48 \sin 6 y$ & Naze & 14 & 15 & 12 17-17-17 \\
\hline 4 Mahrasshtra & PUNE & 1997 & 4 & 4570 Autumn & 26 & 52 & 4 sandy & Maize & 23 & 0 & $2028-28$ \\
\hline 5 Mahrarshitra & PUNE & 1997 & & 4570 Autumn & 33 & 64 & 51 sandy & Naize & 5 & 9 & $2914-35-14$ \\
\hline 6 Mahrarshitra & PUNE & 1997 & & 4570 Autumn & 30 & 60 & 47 Sandof & Maize & 20 & 0 & 2128.28 \\
\hline Maharashtra & PUNE & 1997 & & 4570 Autumn & 28 & 54 & $25 \sinh \frac{1}{2}$ & Maire & 9 & 10 & $301435 \cdot 14$ \\
\hline 8 Mharasshtra & PUNE & 1997 & 400 & 470 Kharif & 26 & 52 & $38 \sin 0 \%$ & Maine & 37 & 0 & OU urea \\
\hline 9 Mahrarshitra & PUNE & 1997 & 400 & 4700 Karaif & 31 & 62 & $48 \operatorname{sendy} y$ & Maize & 14 & 15 & 1217-17.17 \\
\hline 10 Mahrasshtra & PUNE & 1997 & 400 & 4700 Khariff & 26 & 52 & 44 sando & Mare & 23 & 0 & 2022828 \\
\hline 11 Mahrasshtra & PUNE & 1997 & 400 & 4700 Khariff & 33 & 64 & 51 sandy & Maine & 5 & 9 & $2914-35-14$ \\
\hline 12 Mahrarshtra & PUNE & 1997 & 400 & 4700 Khariff & 30 & 60 & 47 Sandoy & Waire & 22 & 0 & 212828 \\
\hline 13 Mahrarshitra & PUNE & 1997 & 400 & 4700 Kararf & 28 & 54 & $25 \operatorname{sindy} 4$ & Naire & 9 & 10 & $301435-14$ \\
\hline 14 Mahrarshitra & PUNE & 1997 & 6900 & 103000 Rabi & 26 & 52 & $38 \operatorname{sen} 0 y$ & Naire & 37 & 0 & OUrea \\
\hline 15 Mahrarshitra & PUNE & 1997 & 6900 & 10300 Rabi & 31 & 62 & 485 sandy & Naine & 14 & 15 & 12 17-17-17 \\
\hline 16 Mhararshitra & PUNE & 1997 & 6900 & $10300 \mathrm{rabi}$ & 26 & 52 & 4 Sanof & Waice & 23 & 0 & 2022828 \\
\hline 17 Mharasshtra & PUNE & 1997 & 6900 & 10300 Rabi & 33 & 64 & 51 sandor & Maire & 5 & 9 & $2914-455 \cdot 14$ \\
\hline 18 Mahrarshitra & PUNE & 1997 & 6900 & 10300 Rabi & 30 & 60 & 47 Sandy & Maice & 22 & 0 & $2128-28$ \\
\hline 19 Mahrasshtra & PUNE & 1997 & 6900 & 10300 Rabi & 28 & 54 & $25 \sin 0 y$ & Maze & 9 & 10 & $3014355 \cdot 14$ \\
\hline 20 Meharassitra & PUNE & 1997 & 1200 & 2000 Sumner & 26 & 52 & $38 \operatorname{sen} \delta y^{2}$ & Matre & 37 & 0 & OU Urea \\
\hline 21 Mahrarshtta & PUNE & 1997 & 1200 & 2000 Summer & 31 & 62 & $48 \operatorname{sen} 6 y$. & Maize & 14 & 15 & $1217-17-177$ \\
\hline 22 Mehrarshitra & PUNE & $199 ?$ & 1200 & 2200 Summer & 26 & 52 & 4 S sandy & Maize & 23 & 0 & $2028-28$ \\
\hline 23 Mahrarshitra & PUNE & 1997 & 1200 & 2200 Summer & 33 & 64 & 51 Sandor & Naire & 5 & 9 & $2914-355 \cdot 14$ \\
\hline & PUNE & 1997 & 12000 & 2000 Summer & 30 & 60 & $47 \sin \delta_{1}$ & Maize & 22 & 0 & 12282.28 \\
\hline 5 Mahrarshtra & PUNE & 1997 & 1200 & 22000 Summer & 28 & 54 & $25 \operatorname{sen} \alpha y$ & Maire & & & $301435-14$ \\
\hline
\end{tabular}

Fig. 6. Final Dataset 
As shown in figure 6, the final prepared dataset contains the following parameters- State_Name, District_Name, Crop_Year, Season, Crop, Area, Temperature, Humidity, Moisture, Soil Type, Nitrogen, Potassium, Phosphorous, Fertilizer Name for the Pune district. Out of all these parameters for crop recommendation, State_Name, District_Name, Crop_Year, Season, Temperature, Humidity, Moisture, Soil Type, Crop parameters were used.

\section{Algorithm Performance:}

Four classification algorithms such as Decision Tree, Random Forest, Naive Bayes, and XGBoost classifiers were used for crop prediction.

TABLE II. ALGORITHM PERFORMANCE

\begin{tabular}{|c|c|c|}
\hline Techniques & $\begin{array}{c}\text { Training } \\
\text { Accuracy }\end{array}$ & $\begin{array}{c}\text { Testing } \\
\text { Accuracy }\end{array}$ \\
\hline Decision Tree Classifier & $100 \%$ & $91.89 \%$ \\
\hline $\begin{array}{c}\text { Decision Tree Classifier } \\
\text { With Hyperparameter Tuning }\end{array}$ & $100 \%$ & $91.89 \%$ \\
\hline Random Forest Classifier & $100 \%$ & $91.89 \%$ \\
\hline $\begin{array}{c}\text { Random Forest Classifier } \\
\text { With Hyperparameter Tuning }\end{array}$ & $100 \%$ & $94.59 \%$ \\
\hline Gaussian Naive Bayes Classifier & $88.07 \%$ & $78.38 \%$ \\
\hline XGBoost Classifier & $100 \%$ & $94.59 \%$ \\
\hline $\begin{array}{c}\text { XGBoost Classifier } \\
\text { With Hyperparameter Tuning }\end{array}$ & $100 \%$ & $97.3 \%$ \\
\hline
\end{tabular}

As shown in Table II, except Gaussian Naïve Bayes Classifier other techniques such as Decision Tree, Random Forest, and XGBoost classifiers gave 100\\% accuracy on training data with Hyperparameter Tuning and without Hyperparameter Tuning. Where Gaussian Naïve Bayes Classifier gave $88.07 \backslash \%$ accuracy on the training dataset. The accuracy of the Decision Tree classifier with and without hyperparameter tuning and Random Forest algorithm without hyper parameter tuning was $91.91 \%$ and Random Forest algorithm with hyper parameter tuning was $94.591 \%$ on test data. The accuracy of the Naive Bayes algorithm was $78.381 \%$ on test data. The accuracy of XGBoost Classifier without hyper parameter tuning was $94.591 \%$ and with hyper parameter tuning was $97.31 \%$ on test data. As the XGBoost classifier gave the highest accuracy as compared to other algorithms, hence the final model was developed using the XGBoost classifier. Same is depicted in figure 7.

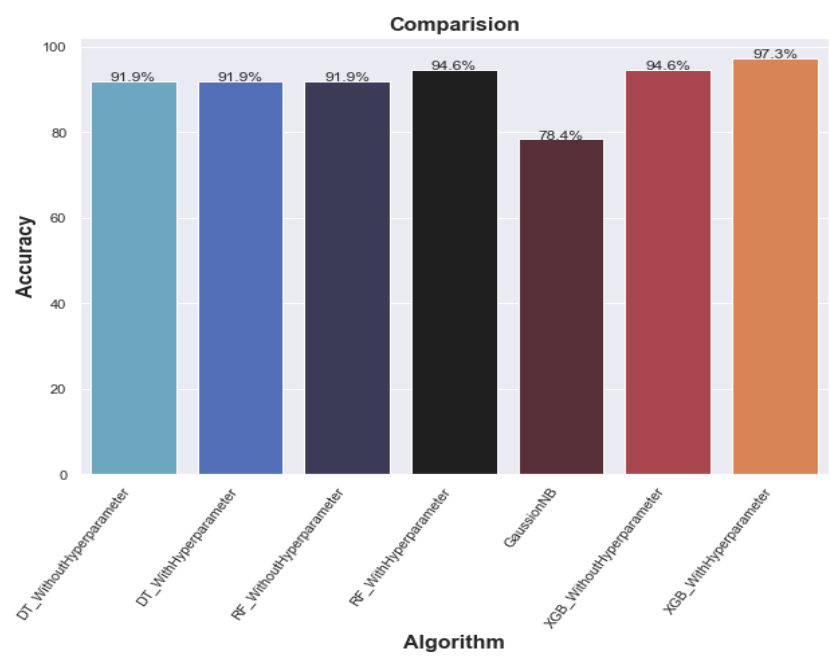

Fig. 7. Performance Analysis
For the recommendation system, the web application is designed using Flask Framework, Python, HTML, and CSS technology.

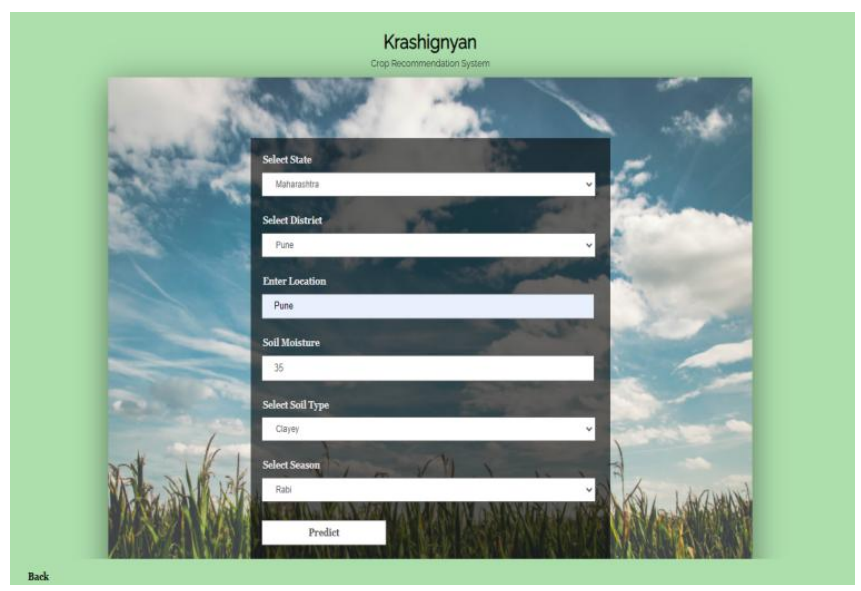

Fig. 8. User Interface

At the front end, the user interface is designed to take user inputs. As shown in Figure 8, the user enters values for location, type of soil, percentage of soil wetness, and crop sowing season. With the help of weather web API, the temperature and humidity of that specific location are fetch. The model then predicts most suitable crops for cultivation based on the user's input. Figure 9 shows the output of the recommended crops.

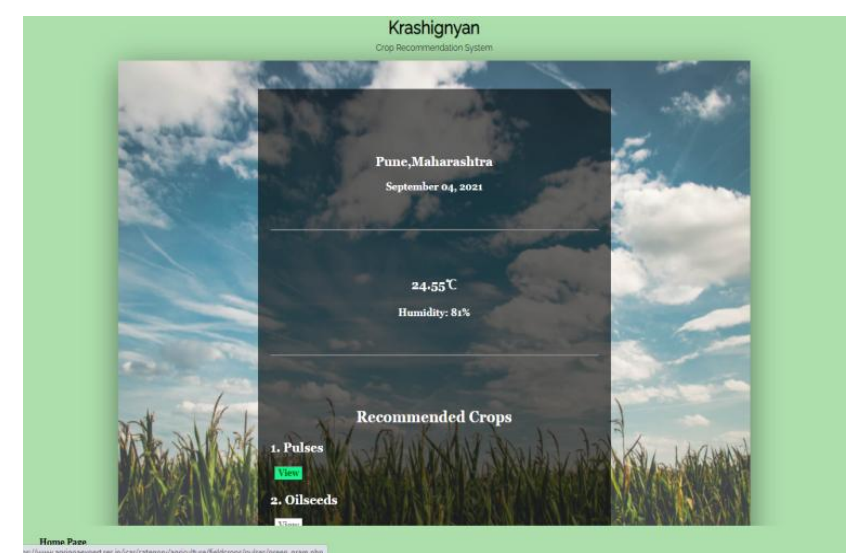

Fig. 9. Crop Recommendation Output

\section{CONCLUSION}

Agriculture has always been an important activity in India because it's not only a source of food but also a source of income for some people. As a result, in order to boost agricultural production, it must be done efficiently. There are various factors that affect crop growth, so choosing the right crop will always increase crop productivity. A crop recommendation system is proposed to help farmers in selecting the best crop for cultivation based on their location, soil factors, and weather parameters. Various machine learning approaches were used, such as decision tree classification, random forest classification, Naive Bayes classifier, and XGBoost classifier. Out of them, the XGBoost classifier gives the best results with a 97\% accuracy, hence the final model was developed using the XGBoost classifier. In the future, for crop recommendation, more soil parameters are going to be considered and the system is further extended with IoT technology to take realtime values of soil parameters for more precise results. 


\section{REFERENCES}

[1] Archana, K., \& Saranya, K. G. (2020). Crop Yield Prediction, Forecasting and Fertilizer Recommendation using Voting Based Ensemble Classifier. SSRG Int. J. Comput. Sci. Eng, 7.

[2] Chaudhari, A., Beldar, M., Dichwalkar, R., \& Dholay, S. (2020, September). Crop Recommendation and its Optimal Pricing using ShopBot. In 2020 International Conference on Smart Electronics and Communication (ICOSEC) (pp. 36-41). IEEE.

[3] Kevin Tom Thomas, Varsha S, Merin Mary Saji, Lisha Varghese, Er. Jinu Thomas. Crop Prediction Using Machine Learning. International Journal of Future Generation Communication and Networking. Vol. 13, No. 3, (2020), pp. 1896-1901.

[4] Lavanya, B., Nisarga, B., Meghana, B. S., \& Mythresh, A. CROP PREDITION USING MACHINE LEARNING.

[5] Nischitha K, Dhanush Vishwakarma, Mahendra N, Ashwini, Manjuraju M.R. Crop Prediction using Machine Learning Approaches. International Journal of Engineering Research \& Technology (IJERT). Vol. 9 Issue 08 (August-2020).

[6] [6] Kulkarni, N. H., Srinivasan, G. N., Sagar, B. M., \& Cauvery, N. K. (2018, December). Improving Crop Productivity Through A Crop Recommendation System Using Ensembling Technique. In 2018 3rd International Conference on Computational Systems and Information Technology for Sustainable Solutions (CSITSS) (pp. 114-119). IEEE.

[7] Mythresh A, Lavanya B, Meghana BS, Nisarga B (2020). Crop Prediction using Machine Learning. International Research Journal of Engineering and Technology (IRJET), 7(6).

[8] Pudumalar, S., Ramanujam, E., Rajashree, R. H., Kavya, C., Kiruthika, T., \& Nisha, J. (2017, January). Crop recommendation system for precision agriculture. In 2016 Eighth International Conference on Advanced Computing (ICoAC) (pp. 32-36). IEEE.

[9] Shinde, M., Ekbote, K., Ghorpade, S., Pawar, S., \& Mone, S. (2016). Crop recommendation and fertilizer purchase system. International
Journal of Computer Science and Information Technologies, 7(2), 665-667.

[10] Kumar, A., Sarkar, S., \& Pradhan, C. (2019, April). Recommendation system for crop identification and pest control technique in agriculture. In 2019 International Conference on Communication and Signal Processing (ICCSP) (pp. 0185-0189). IEEE.

[11] [11] Banavlikar, T., Mahir, A., Budukh, M., \& Dhodapkar, S. (2018). Crop recommendation system using Neural Networks. International Research Journal of Engineering and Technology (IRJET), 5(5), 1475-1480.

[12] Doshi, Z., Nadkarni, S., Agrawal, R., \& Shah, N. (2018, August). AgroConsultant: Intelligent Crop Recommendation System Using Machine Learning Algorithms. In 2018 Fourth International Conference on Computing Communication Control and Automation (ICCUBEA) (pp. 1-6). IEEE.

[13] Kalimuthu, M., Vaishnavi, P., \& Kishore, M. (2020, August). Crop prediction using machine learning. In 2020 Third International Conference on Smart Systems and Inventive Technology (ICSSIT) (pp. 926-932). IEEE.

[14] Patil, A., Kokate, S., Patil, P., Panpatil, V., \& Sapkal, R. (2020). Crop Prediction using Machine Learning Algorithms. Kapila Journals, 1(1), 1-8.

[15] Dhruv Piyush Parikh, Jugal Jain, Tanishq Gupta and Rishit Hemant Dabhade. Machine Learning Based Crop Recommendation System. International Journal of Advanced Research in Science, Communicationand Technology (IJARSCT), Volume 6, Issue 1, June 2021.

[16] https://en.wikipedia.org/wiki /Agriculture_in_India

[17] https://www.kaggle.com/gdabhishek/fertilizer-prediction

[18] https://www.kaggle.com/anjali21/agricultural-production-india

[19] https://data.gov.in/catalog/district-wise-season-wise-crop-production 